\title{
Using an Emergency Department Syndromic Surveillance System to Assess the Impact of Cyclone Bejisa, Reunion Island
}

\author{
Pascal Vilain*1, Frédéric Pagès ${ }^{1}$, Katia Mougin-Damour ${ }^{2}$, Xavier Combes ${ }^{3}$, Pierre-Jean \\ Marianne Dit Cassou ${ }^{4}$, Yves Jacques Antoine ${ }^{5}$ and Laurent Filleul ${ }^{1}$
}

${ }^{1}$ Regional Office of French Institute for Public Health Surveillance in Indian Ocean, Saint-Denis, Réunion; ${ }^{2} \mathrm{Hospital}$ Centre, SaintPaul, Réunion; ${ }^{3}$ University Hospital Centre, Saint-Denis, Réunion; ${ }^{4}$ University Hospital Centre, Saint-Pierre, Réunion; ${ }^{5}$ Hospital Centre, Saint-Benoît, Réunion

\section{Objective}

To assess the health impact of cyclone Bejisa from data of emergency departments (EDs) and emergency medical service (EMS)

\section{Introduction}

On January 2, 2014 the cyclone Bejisa struck Reunion Island. This storm of Category 3 (Saffir-Simpson scale) disturbed electricity supply and drinking water systems. Floods, roof destructions and the threat of landslide led to the evacuation of residents to emergency shleters. In this context, the regional office of French Institute for Public Health Surveillance in Indian Ocean set up an epidemiological surveillance in order to assess the impact in the aftermath of the cyclone.

\section{Methods}

Short-term health effects were assessed using a syndromic surveillance system including the activity of all EDs and the EMS of the island ${ }^{1}$. From these data, several health indicators were collected and monitored. Daily indicators were analyzed using the $\mathrm{C} 2$ aberration detection algorithm and weekly indicators, the threshold was defined using the method of Farringhton. To complete this assessment, a field investigation was carried out in EDs. All medical files recorded in the EDs of Reunion Island from January 2 to 5, 2014 were reviewed in order to identify visits related to the cyclone and to determine mechanisms of injuries.

\section{Results}

The number of calls to the EMS peaked the day of the cyclone and the number of ED visits increased markedly over the next two days. At the same time, a significant increase of visits for trauma, burns, conjunctivitis was observed on all EDs (Figure 1). Six visits for carbon monoxide poisoning were detected in the southern ED. Epidemiological investigations allowed to identify an inappropriate use of generator. Among 1748 medical records reviewed, 216 visits were related to the cyclone. Injuries represented nearly half of these visits. The main mechanisms of trauma were falls and injuries by machinery or tools during the clean-up and repair works. Due to prolonged power outage, several patients were hospitalized: some to assure continuity of care, others to take care of an exacerbation of a chronic disease.

\section{Conclusions}

The reactivity and the flexibility of the syndromic surveillance system based on the near real-time transmission of data from EDs allowed to rapidly assess the health impact of the cyclone Bejisa in Reunion Island, the syndromic surveillance system appears to be an adapted response in this context ${ }^{2}$. However an underestimation of this impact was still possible. In the near future several work leads will be planned in order to improve the assessment.

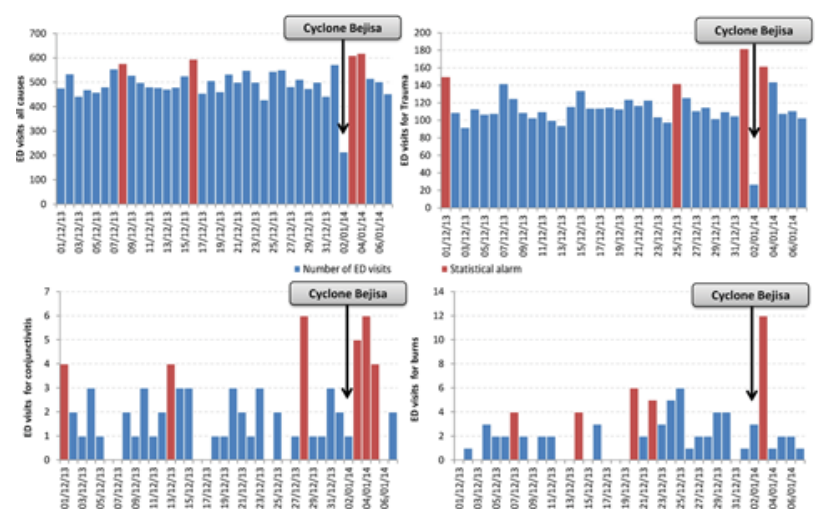

Figure 1. Daily number of ED visits for trauma, burns, conjunctivitis and all causes, December 1, 2013 to January 7, 2014.

\section{Keywords}

Syndromic surveillance; Natural disasters; Public Health Reports

\section{Acknowledgments}

We acknowledge all practitioners of emergency departments and emergency medical service.

\section{References}

1.Vilain P, L Filleul. La surveillance syndromique à la Réunion : un système de surveillance intégré. [Syndromic surveillance in Reunion Island: integrated surveillance system]. Bulletin de Veille Sanitaire. 2013;(21):9-12. http://www.invs.sante.fr/ Publications-et-outils/Bulletin-de-veille-sanitaire/Tous-les-numeros/ Ocean-indien-Reunion-Mayotte/Bulletin-de-veille-sanitaire-oceanIndien.-N-21-Septembre-2013. Accessed August 12, 2014.

2.Hope K, Merritt T, Eastwood K, Main K, Durrheim DN, Muscatello D, Todd $\mathrm{K}$, Zheng $\mathrm{W}$. The public health value of emergency department syndromic surveillance following a natural disaster. Commun Dis Intell Q Rep. 2008;32(1):92-4.

\section{*Pascal Vilain \\ E-mail: pascal.vilain@ars.sante.fr}

